\title{
Healthcare Associated Infections: Nuisance in the Modern Medical Epoch
}

\author{
Aamer Ikram ${ }^{1}$ and Luqman Satti ${ }^{2}$ \\ ${ }^{1}$ Department of Pathology, Quetta Institute of Medical Sciences \\ ${ }^{2}$ Combined Military Hospital, DI Khan \\ Pakistan
}

\section{Introduction}

Rapid advancements in the medical sciences have changed the understanding of the diseases down to the molecular level and in turn revolutionized the diagnostics and therapeutics. Similarly, architectural and engineering progression has reshaped the outlooks of the hospitals with the aim of comforting the patients. Despite all that, hospital environments remain a source of infection for the already ailing clientele. The scare of 'super bugs' has further aggravated the situation requiring more consolidated efforts for protection of admitted patients.

Healthcare associated infections (HAIs) are major cause of increased morbidity and mortality (World Health Organization [WHO], 2009). Statistics of various surveys show that 1 out of 10 patients admitted in hospital invariably acquire HAI (Emmerson, 1995). Data from developing countries is sparse, the situation otherwise seems to be much higher as compared to the developed world (Allegranzi et al., 2011). Worldwide around 1.4 million people are affected by HAIs at any given instance (Pittet \& Donaldson, 2005). HAIs account for 99,000 deaths in American hospitals according to the Centres for Disease Control \& Prevention (CDC) estimates (Klevens et al., 2007), and 37,000 deaths in Europe (WHO, 2011).

HAI or nosocomial infection is defined as localized or systemic infection which reveals itself in patient either during stay in hospital or after discharge, and was not incubating at the time of admission (WHO, 2002). Hospital infection control (HIC) refers to combination of various guidelines, policies and modalities implemented to minimize the risk of spreading infections in a health care facility. In the past, HAIs were restricted only to the hospital environments but in the recent years, various healthcare settings such as ambulatory care, home care have also been included in this category. This chapter essentially focuses on the prime aspects of HAIs especially lately documented.

These unanticipated but otherwise preventable infections have many distressing consequences such as increased mortality, prolonging morbidity and hospital stay, additional diagnostic and therapeutic interventions adding financial burden not only for the patient but also significant economic consequences on the entire healthcare organization. HAIs thus have a negative impact on the patients and their families and in turn the system. The financial effect is humongous as it has been estimated to reach $£ 1,000$ million each year 
in the UK (National Audit Office [NAO], 2000), $€ 7$ billion in Europe (WHO, 2011) and \$ 6.65 billion in the US in 2007 (Scott, 2009).

In the recent years, duration of patients' hospital stay has decreased but paradoxically, HAIs are increasing at alarming rates (Burke, 2003; Stone et al., 2002). Unfortunately, exact incidence of HAIs is not known or undervalued as many patients develop symptoms after discharge from the hospitals especially post-surgical infectious cases. Intensive care units (ICUs) and surgical units are the main reservoirs for HAIs especially in resource poor countries; reason being that most of the patients, especially in ICUs, have meager immunity or are critically ill (Ikram et al., 2010). However, the main reason for HAIs remains poor adherence to 'standard infection control guidelines' and 'additional precautions' (Siegel, 2007). Any breach in the infection control practices augments the transmission of microorganisms. It is, therefore, obligatory for everyone including doctors, nurses, paramedics, patients and even visitors to strictly follow the standard infection control guidelines.

The sites involved and the sources could be multiple. Surgical site infections comprise $20 \%$ of HAIs and around 5\% of operated patients develop these infections (de Lissovoy et al., 2009; Gottrup, 2000). Neonatal nosocomial infection doubles the mortality risk and can only be improved by paying comprehensive attention to all aspects of neonatal intensive care (Gill et al., 2011).

Invasive fungal infections in hospitalized patients increase morbidity and mortality. Candida spp. is responsible for $15 \%$ of HAIs and $72 \%$ of nosocomial fungal infections, and invasive candidiasis has mortality rate up to $40-50 \%$ in hospitalized patients (Gudlaugsson et al., 2003). Water in the dental units may be contaminated with a variety of organisms which may in turn cause infection during dental procedures (Kumar et al., 2011).

\section{Responsibility of infection control team}

Infection control in a health care setting requires a multifaceted approach (CDC, 2007) and is responsibility of everyone coming in contact with the patient. The pivotal role is performed by a committed Infection Control Team usually comprising:

- Infection control practitioner or doctor.

- Administrator.

- Infection control nurse.

Infection Control Team is responsible for establishing infection control policies and procedures, providing advice and guidance regarding infection control matters, regular audits and surveillance, identification and investigation of outbreaks, awareness and education of staff (Ayliffe et al., 2000). The team works under Infection Control Committee which chiefly carries the responsibilities of making major decisions, problem discussion with the team, departmental coordination, educational activities, policy modification and recommendations.

\section{Factors implicated in healthcare associated infections}

Factors predisposing a hospitalized patient to HAI are related to organisms, host and environments. 


\subsection{Organism-related factors}

Practically any microorganism in the vicinity can cause HAI; varying for different settings, populations and countries (WHO, 2002). The organisms may be endogenous causing autoinfection or self-infection, or exogenous. The exogenous organisms are usually transferred through airborne, percutaneous or direct contact transmission. 'Cross-infection' is transmission of organism from one person to another. Organisms commonly responsible for major HAIs are listed in table 1.

\begin{tabular}{|l|l|}
\hline \multicolumn{1}{|c|}{ Type of Infection } & \multicolumn{1}{c|}{ Common organisms involved } \\
\hline $\begin{array}{l}\text { Surgical site infections } \\
\text { (SSIs) }\end{array}$ & $\begin{array}{l}\text { S. aureus, Enterococcus spp, S. pyogenes, E. coli, Pseudomonas } \\
\text { aeruginosa, Proteus spp and anaerobes }\end{array}$ \\
\hline $\begin{array}{l}\text { Blood stream infections } \\
\text { (BSIs) }\end{array}$ & $\begin{array}{l}\text { S. aureus including methicillin resistant S. aureus (MRSA), } \\
\text { coagulase negative staphylococci and Enterococcus spp }\end{array}$ \\
\hline $\begin{array}{l}\text { Urinary tract infections } \\
\text { (UTIs) }\end{array}$ & $\begin{array}{l}\text { E. coli, Proteus spp, Klebsiella spp, Pseudomonas aeruginosa, } \\
\text { Serratia spp, Enterococcus spp and less commonly C. albicans }\end{array}$ \\
\hline $\begin{array}{l}\text { Ventilator associated } \\
\text { pneumonia (VAP) }\end{array}$ & $\begin{array}{l}\text { Acinetobacter baumannii, Pseudomonas aeruginosa, S. aureus, and } \\
\text { Enterobacteriaceae }\end{array}$ \\
\hline
\end{tabular}

Table 1. Common organisms involved in healthcare associated infections.

Serratia marcescens has been associated with nosocomial outbreaks mostly with contaminated fluids and injections. Recently there has been an outbreak among newborns due to usage of contaminated baby shampoo (Madani et al., 2011). Clostridium difficile associated diarrhoea (CDAD) is associated with high mortality rate in hospitalized patients particularly elderly with multiple co-morbidities (White and Wiselka, 2011). Acinetobacter baumannii has rapidly emerged as a nosocomial pathogen and that too with acquisition of multidrug resistance. Anti-pseudomonal carbapenems have been utilized against this resistant species, however, one-half to two-third of the isolates have been reported as resistant to this group as well (Tsakris et al., 2006).

Viral infections can be transmitted through different routes in the healthcare settings; airborne viruses such as influenza virus, respiratory syncytial virus, adenovirus, rhinovirus, coronavirus, measles, rubella virus, mumps virus and parvovirus B19 can spread through droplets or indirectly by settling on surfaces; faecal-oral route such as norovirus, rotavirus and human adenovirus 40 and 41 (Lopman et al., 2004); and blood-borne like hepatitis B and C viruses and human immunodeficiency virus (Davanzo et al., 2008).

\subsection{Host-related factors}

The host could either be a patient or staff. There are numerous risk factors which predispose a host to acquire HAIs including:

- $\quad$ Low body resistance as in infancy and old age.

- Underlying illness gravity - patients with severe diseases / debilitated conditions.

- Prolonged hospitalization. 
- Delayed hospital discharge has been associated with increased HAI prevalence. The reason for delayed discharge include long term bed care, pending equipment required at home or access to other services (McNicholas et al., 2011).

- Immunosuppression, malignancy, pregnancy.

- Reduced local tissue resistance.

- Use of medical devices such as I/V cannula, catheters, shunts and procedures such as bronchoscopy, cystoscopy etc.

\subsection{Environment-related factors}

Environment has a very significant impact on the chances of acquiring HAI and it varies for different places within a hospital. Clean and healthy environments in wards and sterile conditions especially in ICUs, nurseries and operation theatres minimize the risk of HAIs.

Routine cleaning and disinfection is not sufficient in hospitals with continuous flow of patients, healthcare workers (HCWs) and visitors, and more efficient methods may have to be adopted to maintain the requisite standards (Wang et al., 2010).

\section{Mode of transmission of microorganisms}

It is important to understand the mode of transmission of microorganisms for putting barricades in the chain at healthcare settings. These include (CDC, 1998; 2007):

\subsection{Droplet transmission}

Droplet particles, produced by coughing, sneezing and even talking, can settle either on surrounding surfaces or on the body mucosa which can be transferred to others. Examples include meningitis and pneumonia.

\subsection{Airborne transmission}

Particles less than 5 micrometers remain suspended in air and may be inhaled causing infection in a susceptible host. Examples are tubercle bacilli and varicella virus.

\subsection{Contact transmission}

This is the most common mode of transmission of organisms which can be direct or indirect. In direct transmission, organisms are transferred from an infected or colonized person to another susceptible host by direct skin contact. In indirect transmission, organisms are first transferred from an infected person to a normal host such as a HCW and then to another. Most common example of contact transmission seen in surgical settings is the transfer of $S$. aureus from an infected wound or boils.

\subsection{Vector-borne transmission}

This mode is unusual in developed countries but it is not so uncommon in resource poor healthcare settings. Organisms are spread by vectors such as flies, mosquitoes and fleas. A common example is spread of dysentery caused by Shigella spp. through flies. 


\subsection{Other modes}

There are sometimes incidences where the source of infection in hospital setting is common and many persons get infected through the same source like use of contaminated food, drinking water, ointments, topical solutions and instruments. This can lead to outbreak in hospital setting.

\section{Principles for hospital infection control}

In general, infection control measures particularly revolve around the following:

- Policies and procedures taken within hospital in different settings such as ICUs, operation theatres, other high risk areas, wards, etc.

- Dedicated infection control teams.

- Maintaining hospital hygiene.

- Effective sterilization and disinfection techniques.

- Proper management of hospital waste.

- Continuous surveillance.

- Outbreak investigation and management in hospital.

- Clinical auditing.

\subsection{Measures taken in hospital}

These include standard infection control measures and transmission based precautions (CDC, 2007). Standard infection control measures are universally accepted and followed in most healthcare facilities.

\subsubsection{Hand washing and hand hygiene}

Hand hygiene is one of the key measures for preventing HAIs (Pittet \& Boyce, 2001). Hand washing between patient contact and after surgical/invasive procedures is the most simple, economical and easy to perform measure significantly reducing infection transmission. However, its practice and compliance has been the core issue worldwide especially in the developing countries (Collins, 2008). Poor hand hygiene practices in hospital has led to number of outbreaks and adverse outcomes (Jarvis, 2001; Stanton and Rutherford, 2004; Hugonnet et al., 2004). It has been well established that simple hand washing with soap and water can prevent majority of childhood illnesses causing high mortality (Luby et al., 2005). Provision of sinks at various places in hospitals, monitoring of hand hygiene and continued education of staff in hospital can increase the level of patient safety. Hand washing and hand hygiene practices can be improved and monitored by using guidelines, 'How-to-Guide: Improving Hand Hygiene' (Institute for Healthcare Improvement, 2008). A versatile approach involving HCWs in the form of social marketing or especially directed towards barriers to hand hygiene seems to be much more successful (Forrester et al., 2010).

Preoperative hand scrubbing by surgical team is mandatory to prevent surgical site infection along with wearing of gloves, gown, mask and cap. A latest study recommends appropriate disinfectant application to forearms for $10 \mathrm{~s}$ as part of preoperative hand disinfection (Hubner et al., 2011). Another study recommends alcohol-based hand rubs for surgical 
preparation because of prompt antimicrobial action, broad spectrum, lesser side effects and avoiding the risk of contamination by the rinsing water (Widmer et al., 2010).

Importance associated with hand hygiene awareness requires national commitment. It is mandatory part of national infection control programmes in many countries. A baseline survey of activities in improving hand hygiene was conducted by the WHO First Global Patient Safety Challenge in 2007. In 2009, it was repeated to evaluate the latest situation. Promotion of hand hygiene has become an important initiative with most of the countries; however, coordinated efforts are to be strengthened across the world (Mathai et al., 2011). WHO message remains - 'Clean hands are safer hands'.

Wearing wrist watches augments the bacterial contamination of the wrist but until it is manipulated, excess hand contamination does not ensue (Jeans et al., 2010). The wearing of watch over the chest pocket is definitely preferable.

In demanding situations like patient overload or in critical care units, alcohol based hand rub may be a more realistic approach as it acts rapidly, takes less time and less irritable (Pittet \& Boyce, 2001). Goroncy-Bermes et al. (2010) recommended $3 \mathrm{~mL}$ of alcohol hand rub containing adequate active concentration for contact time of $30 \mathrm{~s}$. In general, sufficient amount should be utilized to cover all the surfaces of both the hands. Increased application of alcohol hand rub has been associated with noteworthy reduction in MRSA rates in hospital settings (Sroka et al., 2010)

Much valuable time of HIC experts has been spent in the development and implementation of audit tools for hand hygiene. Gould et al (2011) recommended a combined approach of routine screening from product uptake and utilization of infection control experts. A promising consideration adjunct to the safety culture is involvement of patients in the design and promotion of hand hygiene at the institutional level (Pittet et al., 2011).

\subsubsection{Physical precautions}

Personal clothing is changed after arriving in the hospital and varies for different departments and hospitals. The indication for changing clinical attire is not as intense as other infection control measures like hand hygiene but it should be part of measures for controlling infections and the concept of 'bare below elbows' may be preferred (Shelton et al., 2010).

Personal protective equipment (PPE) is used by healthcare workers for protection against infectious organisms as it acts as a barrier between the worker and fluid or material containing infectious agents. PPE may comprise of gloves, mask/respirator such as N-95, gowns/apron, goggles/face shield, shoe and head covers. Some of the important aspects for proper PPE utilization are:

- Risk assessment is an important aspect before deciding about the sort of PPE to be utilized. PPE should be selected according to the risks involved in that particular healthcare setting.

- $\quad$ PPE should not be worn outside the restricted area. There should be properly allocated place for every HCW for keeping PPE.

- $\quad$ Each HCW should have his/her own PPE. 
- $\quad$ PPE should be changed between patients' contact followed by proper hand washing.

- Used or old PPE should be disposed of properly.

- Double gloving should be done where indicated and punctured gloves should be changed immediately.

Healthcare setting environments can be protected by provision of physical barriers in the form of isolation of infected cases. Isolation policy and guidelines for the infectious cases thus remain pivotal for curtailing pathogen spread and have to be prepared according to requirements considering transmission mode, risk of spread to others, severity of infection, effective treatment available, and impact of isolation on patients (Ayliffe et al., 1999). Cohorting of the patients infected with same pathogen can be done.

\subsubsection{Environmental safeguards}

Hospital environments hold a diverse group of microorganisms surrounding a patient which generally originates from normal flora of patient, HCW, visitor, or from infected wounds. In the recent years, much debate is going on the role of environmental cleaning in reducing HAIs. The apparent hygiene of hospital cannot be linked with the risk of HAIs. With the emergence of fear and public panic due to 'superbugs' causing serious HAIs, hospital environments have been blamed for such infections. However, the exact role of hospital environment in causing these infections remains unknown (Dancer, 2009). Some of the superbugs such as Acinetobacter baumannii and Pseudomonas aeruginosa, after gaining access to hospital environment especially in ICUs, are extremely difficult to eradicate even with the advanced disinfection techniques. Hospital room surfaces and inanimate objects such as blood pressure set, stethoscope, utensils, etc can become colonized with resistant microorganisms such as MRSA, VRE and Clostridium difficile. Ungloved hands can become $50 \%$ more contaminated with low level pathogenic microorganisms (Bhalla et al., 2004).

For prevention of health associated infections particularly in immuno-compromised patients, special attention should be directed to the quality of air circulating in the hospital environments (Leung and Chan, 2006). Total air change rate should be 15 air changes/hr for operation theatres and delivery rooms; 6 air changes/hr for intensive care units, isolation rooms and laboratories; and 4 air changes/hr for patient rooms. Isolation room, equipment sterilization room and laboratory should have negative pressure control while intensive care unit, operation theatre and delivery room should have positive pressure control. The flow of air has to be from clean towards dirty areas. A latest study by Tang et al. (2011) has nicely observed the role of airflow patterns and movement of suspended material in infection control of aerosol and airborne transmitted diseases employing different techniques. This understanding would be very beneficial in understanding aerosol and airborne infection transmission through precise airflow visualization techniques and in turn developing modalities for preventing them.

Among many sources responsible for nosocomial infections, hospital water is a controllable but overlooked source. Many pathogens can survive in hospital water supply, transfer antibiotic resistance and have been implicated in numerous outbreaks (Anaissie et al., 2002). Proper guidelines for the monitoring and prevention of hospital water borne infections are still limited. Legionella pneumophila, pathogenic mycobacteria, parasites and viruses have been implicated in hospital water borne diseases. In the recent years, pathogenic fungi and 
molds have been increasingly reported (Falvey \& Streifel, 2007; Garner \& Machin, 2008) thus mounting the need to formulate guidelines for the monitoring of hospital water sources (Hayette et al., 2010). Avoidance of hospital tap water, routine and targeted surveillance cultures of water sources, and hospital staff and patients education are major measures to control water associated nosocomial infections. Marchesi et al. (2011) employed hyperchlorination, thermal shock, chlorine dioxide, monochloramine, boilers and point-ofuse filters to control Legionella spp. in hospital water supply.

The make of surfaces of hospital items does affect the contamination chances. Coppercontaining items tend to reduce the number of microbial surface contamination in hospital environments (Casey et al., 2010). The antimicrobial activity of copper-containing surfaces has been demonstrated to be far more effectual as it decreases the biodurden to a far greater amount as compared to the standard materials (Marias et al., 2010). The routine cleaning of these surfaces, however, is mandatory and the make of surfaces act as additional factors against HAIs.

Central venous catheters are justifiably used in the ICUs whereas reverse is true for non-ICU settings and even for prolonged periods facilitating infections. There is a dire need to prevent infections associated with CVCs and short-term indwelling catheters. Measures should be targeted at insertion time with judicious usage of CVCs in these settings as part of strategy to reduce HAIs (Zingg et al., 2011).

\subsubsection{Control of multidrug resistant organism}

Multidrug resistant (MDR) organisms in hospital settings add further impetus to the status of HAIs. Empirical use of costly and broad spectrum antibiotics against these organisms further augments their resistance potential. For example, it is much more difficult to treat ventilator associated pneumonia due to MDR Acinetobacter baumannii in an ICU than a sensitive strain. A multicentric study showed that bacteremia caused by MRSA strain is associated with higher mortality and prolong hospital stay than caused by methicillin sensitive strain (Cosgrove et al., 2003).

During the past decade, MDR organisms have emerged at an alarming level especially in intensive care units. In these settings, MRSA infections have been dominant with $60 \%$ of all the staphylococcal infections followed by VRE, $20 \%$ of all the enterococcal infections; while $31 \%$ of the enterobacter infections were caused by third generation cephalosporin resistant strains (CDC, 2004). Surveillance data in the USA showed that MRSA accounts for $64 \%$ of the invasive nosocomial infections due to $S$. aureus. Various studies have shown that the data of frequency of MDR organisms outside the ICUs is almost similar (Loeb et al., 2003; Trick et al., 2001). Matenez-Capolino et al. (2010) showed that active surveillance cultures with contact precautions augmenting the standard measures could help reducing nosocomial MRSA in healthcare settings.

Strict implementation of HIC guidelines is recommended to prevent the transmission of MDR organisms in hospital environments including:

- Contact precautions, isolation of infected/colonized patients and use of PPE.

- Active surveillance cultures to identify the persons colonized with resistant organisms including HCWs. 
- $\quad$ Stringently following standard precautions and hand hygiene.

- Cohorting of patients infected or colonized with MDR organisms.

Nasal carriage of MRSA by the patients as well as staff remains an important source for infection. Many remedies have been tested for nasal elimination of MRSA including local $2 \%$ mupirocin application which has lead to emergence of resistant strains. Polyhexanide, a widely used antiseptic, has been shown to be an effective alternate to mupirocin in elimination of nasal MRSA especially mupirocin-resistant strains (Madeo, 2010).

\subsubsection{Surveillance}

Surveillance comprises continuing systematic collection, analysis, interpretation and dissemination of data pertaining to health related events to be utilized for improving the health system (CDC, 2001). It is a vital component in HIC chain for avoidance and early detection of outbreaks and in turn prompt response as well as determining the need and measuring outcome of actions already adopted (NAO, 2000). Surveillance can be localized or targeted such as to see ventilator associated pneumonia in an ICU or generalized such as to measure infection rate in a hospital. Financial restraints of a hospital are very important to determine the type of surveillance performed. With transformation in healthcare delivery system and advancement in more friendly electronic tools, surveillance methods will continue progression and facilitate effective infection control measures (CDC, 2007).

Staff working in hospital environments has to be protected from catching infections from patients. There should be a regular health surveillance system, ideally part of occupational health services within the setup. The department should address the needs of HCWs especially regarding relevant vaccination status and any accidental exposure, maintaining proper and timely health records, and requisite guidance and training.

\subsubsection{Hospital antibiotic policy}

Injudicious use of antibiotics especially in hospital settings is a major factor in the development of drug resistant organisms. Each hospital must have its own antibiotic policy based upon the culture and sensitivity results that should be regularly reviewed. Overuse and misuse of antibiotics exerts a selective pressure on bacteria thus resulting in emergence of drug resistance. If possible, usage of newer and costly antibiotics should be restricted to minimum and prescribed only for serious conditions or non-availability of alternate choice in order to prevent the emergence of resistance (Ferguson, 2004). In the recent years, attention has been directed to a greater extent towards prevention through immunization and HIC steps as substitute to reduce the prescription of antibiotics.

Many studies have shown that rational use of antibiotics alone can significantly reduce emergence of drug resistance (Landman et al., 1999; McNulty et al., 1997; Quale et al., 1996; Saurina et al., 2000). In order to reduce emergence of MDR organisms, certain measures should be considered while prescribing antibiotics such as:

- Clinical condition of the patient should be carefully assessed before prescribing any antibiotic.

- Requisite culture and sensitivity results for targeted therapy except in serious infections. 
- Substandard drugs, frequent problem in developing countries, should be prohibited.

- Truly infecting organisms should be treated, not colonizers or contaminants.

- Empirical therapy must be advised in the light of existing local susceptibility pattern.

- Combination therapy should be considered in indicated cases.

- Appropriate antibiotic, preferably narrow spectrum, should be advised in precise dose for proper duration.

- Measures must be instilled for ensuring awareness regarding hospital antibiotic policy.

\subsubsection{Sterilization and disinfection practices}

Hospital sterilization and disinfection policy is crucial and basic component of infection control system. All invasive procedures require direct contact between patient's skin or mucous membrane and medical devices thus carrying a risk of direct transfer of pathogenic organisms. Various steps required to reduce infection rate in hospitals by effective sterilization and disinfection policy include an efficient and dependable team, assessment and implementation of ongoing disinfection policies, adequate staff training and regular audits (Coates and Hutchinson, 1994).

The level of sterilization and disinfection depends on the risk assessment: critical items such as surgical instruments for direct tissue contact require sterilization while semi critical items such as colonoscope with mucous membrane contact and non critical items such as stethoscope with intact skin contact require high level and low level disinfection respectively (Dancer, 2009). Failure to strictly comply with these policies can lead to outbreaks and transmission of pathogenic organisms such as Mycobacterium tuberculosis from one person to another through medical or surgical devices such as contaminated endoscopes (CDC, 1998; Garner and Favero, 1986; Uttley and Simpson, 1994).

Spaulding's devised compact and effective scheme for sterilization and disinfection is still in practice with certain modifications (Weber et al., 2002). Critical items can be purchased as sterile or disposable or treated with steam. Heat sensitive instruments can be sterilized by ethylene oxide, hydrogen peroxide gas plasma sterilization or by liquid sterilents if other methods are not appropriate. One of the disadvantages of liquid sterilents is that the devices cannot be wrapped during processing leading to difficulty in maintaining sterilization after processing and during storage.

In case of semi critical items such as endoscope, colonoscope, respiratory therapy equipment, devices should be free of all the pathogenic organisms with exception of small numbers of bacterial spores. These items require high level disinfection with chemical disinfectants such as glutaraldehyde, hydrogen peroxide, ortho-phthalaldehyde, peracetic acid with hydrogen peroxide, and chlorine. After disinfection, these items should be thoroughly rinsed with sterile water and allowed to dry thus reducing the chances of contamination by eliminating the wet environment favourable for bacterial growth (Garner and Favero, 1986; Spaulding, 1968). Non critical items such as stethoscope, bedpans, bed rails, blood pressure cuff, furniture and floors do not require sterilization or high level disinfection as they come in contact with the intact skin. They do not require separate processing unit and can be disinfected at the same place. There is no documented report of a non critical item causing direct transmission of an infectious agent to patients (CDC, 2003). However, they can contribute to secondary transmission mode by 
contaminating the hands of HCWs and subsequently to the patients. Quaternary ammonium compounds, chlorine based compounds and phenols are some of the commonly used low level disinfectants.

As skin antiseptics prior to venous puncture, alcoholic products appear to be better than non-alcoholic solutions (Caldeira et al., 2011). Spores of C. difficile can contaminate the healthcare settings and require use of appropriate disinfectant. Many available disinfectants like alcohol-containing gels, detergents and quaternary ammonium compounds are ineffective against $C$. difficile spores. Chlorine releasing agents are reliable for its control but with limitations under dirty conditions (Fraise, 2011).

The importance of sporicidal disinfectants can never be undervalued especially under the present circumstances. Commercially available sporicides have to be evaluated through testing standards. Although a number of such standards are available in Europe, these have limitations such as prolonged application time and do not involve surface contamination. Organization for Economic Cooperation \& Development is presently preparing a more realistic set of standards (Humphreys, 2011).

\subsubsection{Hospital waste management}

Proper disposal of hospital waste is the last requisite in the chain of an effective HIC system. The hospital waste is a threat not only for the patients and the concerned staff but also to public health and environment (Singh \& Sharma, 1996). It is a bit neglected part in the developing countries leading to spread of infectious diseases like hepatitis B, hepatitis C.

Hospital waste includes all types of waste generated in a healthcare facility including laboratories. The infectious waste comprises pathological, isolation, laboratory, surgical, autopsy and animal waste, human blood and blood products and contaminated sharps. Others include chemical, genotoxic and radioactive waste. Sharps contaminated with blood are the major risk factors for infection transmission (WHO, 2002).

Calculation of infectious waste output is obligatory for each healthcare setting so as to streamline the final disposal. Studies have shown that in the US, the rate of average waste production is 5.9 to $10.4 \mathrm{~kg} / \mathrm{bed} /$ day while in Western Europe it is around 3-6 kg/bed/day (Brunner, 1986; Halbawach, 1994). Disposal of this infectious waste remains intricate and expensive with special concerns like environmental hazards related to incineration. As such, infectious waste reduction leads to cost reduction (Daschner, 1991).

Various components of hospital waste management include: collection of waste by defined persons, segregation/sorting of waste, transportation, storage and disposal.

\subsubsection{Principles of waste management}

- Dedicated hospital waste management committee is a prerequisite.

- Suitable waste management plan based on risks and types of waste generated.

- Waste minimization is an imperative aspect to be highlighted to HCWs.

- Color coded bags must be utilized according to the type of waste.

- Waste to be transported in trolleys or carts and stored at specified restricted places.

- Sharps should be stored in proper boxes with biohazard sign. 
- Sharps should be first autoclaved and then buried in a secured area after compaction. Animal carcasses and anatomical waste should be incinerated while radioactive waste should be dealt according to the national laws.

\subsubsection{Education and training}

Awareness of the HCWs has to be ensured and updated in the form of regular educative and training activities. Not only that, patients and their relatives have also to be imparted awareness regarding infection control measures in order to break the transmission chain. Healthcare infection control should be a mandatory component of training at postgraduate and undergraduate level for HCWs and also imparted to all others coming in contact with patients or medical equipment (CDC, 2007).

\section{International efforts}

Determined efforts and concern for HAI control at the international level especially by the WHO have to be acknowledged. The material available at the WHO website provides plenty of guidance in this respect. The material can easily be downloaded and utilized in preparing local policies. The global involvement in raising awareness about hand hygiene has been commendable. Similarly, assistance can be sought through abundant valuable information provided by the CDC website. These are truly helpful for the developing world.

Regular live and archived lectures are available through courtesy of Webber Training Inc (www.webbertraining.com). These have ample latest information that can provide guidance to the HCWs especially concerned with infection control.

\section{References}

Allegranzi, B., Nejad, S.B., Combescure, C., Graafmans, W., Attar, H., Donaldson, L., \& Pittet, D. (2011). Burden of endemic healthcare-associated infection in developing countries: systematic review and meta-analysis. Lancet, Vol. 377, pp. 228-241.

Anaissie, E.J., Penzak, S.R., \& Dignani, M.C. (2002). The hospital water supply as a source of nosocomial infections: a plea for action. Arch Intern Med, Vol. 162, No. 13, pp. 1483-1492.

Ayliffe, G.A.J., Babb, J.R., \& Taylor, L.J. (Eds.). (1999). Hospital-acquired infection. Principles and Practice, (3rd Edition), Butterworth and Heinemann, ISBN 0192620339, Oxford.

Ayliffe, G.A.J., Fraise, A.P., Geddes, A.M., \& Mitchell, K. (Eds.). (2000). Control of Hospital Infection, (4 $4^{\text {th }}$ Edition), Arnold, ISBN 0340759119, London.

Bhalla, A., Pultz, N.J., Gries, D.M., Ray, A.J., Eckstein, E.C., Aron, D.C., \& Donskey, C.J. (2004). Acquisition of nosocomial pathogens on hands after contact with environmental surfaces near hospitalized patients. Infect Control Hosp Epidemiol, Vol. 25, No. 2, pp. 164-167.

Brunner, C.R. (1986). Hazardous air emission from incineration. (2nd Edition), Champman \& Hall New York, NY.

Burke, J.P. (2003). Infection control - a problem for patient safety. N Engl J Med. Vol. 25, No. 348, pp. 651-656. 
Caldeira, D., David, C., \& Sampaio, C. (2011). Skin antiseptics in venous puncture-site disinfection for prevention of blood culture contamination: systematic review with meta-analysis. J Hosp Infect, Vol. 77, pp. 223-232.

Casey, A.L., Adams, D., Karpanen, T.J., Lambert, P.A., Cookson, B.D., Nightingale, P., Miruszenko, L., Shillam, R., \& Christian, P. (2010). Role of copper in reducing hospital environment contamination. J Hosp Infect, Vol. 74, pp. 72-77.

Centers for Disease Control \& Prevention. (1996). Guidelines for isolation precautions in hospitals. Hospital Infection Advisory Committee. Accessed on 15 July 2011. Available from: <http://wonder.cdc.gov/wonder/prevguid/p0000419.asp>

Centers for Disease Control \& Prevention. (1998). Ambulatory and inpatient procedures in the United States, 1996. Atlanta, GA, pp. 1-39.

Centers for Disease Control \& Prevention. (2001). Updated Guidelines for Evaluating Public Health Surveillance Systems. Recommendations from the Guidelines Working Group. MMWR Recomm Rep, 50(RR-13), pp. 1-35.

Centers for Disease Control. (2003) Guidelines for Environmental Infection Control in Health-Care Facilities, 2003. MMWR, Vol. 52 (No. RR-10), pp. 1-44.

Centers for Disease Control \& Prevention. (2004). National nosocomial infections surveillance (NNIS) system report, data summary from January 1992 through June 2004, issued October 2004. Am J Infect Control, Vol. 32, pp. 470-85.

Centers for Disease Control \& Prevention. (2007). Guidelines for isolation preventions: preventing transmission of infectious agents in healthcare settings. Accessed on 16 July 2011. Available from:

<http://www.cdc.gov/hipac/pdf/isolation/isoaltion2007.pdf>

Coates, D., \& Hutchinson, D.N. (1994). How to produce a hospital disinfection policy. J Hosp Infect, Vol. 26, No. 1, pp. 57-68.

Collins, A.S. (2008). Preventing Health Care-Associated Infections. In: Patient Safety and Quality: An Evidence-Based Handbook for Nurses. Hughes, R.G. Rockville. Rockville, Agency for Healthcare Research and Quality, US. Accessed on 12 July 2011. Available from: <http://www.ncbi.nlm.nih.gov/books/NBK2683/>

Cosgrove, S.E., Sakoulas, G., Perencevich, E.N., Shwaber, M.J., Karchmer, A.W., \& Carmeli, Y. (2003). Comparison of mortality associated with methicillin-resistant and methicillin-susceptible Staphylococcus aureus bacteremia: a meta-analysis. Clin Infect Dis, Vol. 36, pp. 53-55.

Dancer, S.J. (2009). The role of environmental cleaning in the control of hospital-acquired infection. J Hosp Infect, Vol. 73, No. 4, pp. 378-85. Epub 2009 Sep 1.

Daschner, F. (1991). Unnecessary and ecological cost of hospital infection. J Hosp Infect, Vol. 18, pp. 73-78.

Davanzo, E., Frasson, C., Morandin, M., \& Trevisan, A. (2008). Occupational blood and body fluid exposure of university health care workers. Am J Infect Control, Vol. 36, pp. 753-756.

de Lissovoy, G., Fraeman, K., Hutchins, V., Murphy, D., Song, D., \& Vaughn, B.B. (2009). Surgical site infection: incidence and impact on utilization and treatment costs. Am J Infect Control, Vol. 37, pp. 387-397. 
Emmerson, A.M. The impact of surveys on hospital infection. (1995) J Hosp Infect, Vol. 30, pp. 421-40.

Falvey, D.G., \& Streifel, A.J. (2007). Ten-year air sample analysis of Aspergillus prevalence in a university hospital. J Hosp Infect, Vol. 67, No. 1, pp. 35-41.

Ferguson, J. (2004). Antibiotic prescribing: how can emergence of antibiotic resistance be delayed? Aust Prescr, Vol. 27, pp. 39-42.

Forrester, L.A., Bryce, E.A., \& Mediaa, A.K. (2010). Clean Hands for Life ${ }^{\mathrm{TM}}$ : results of a large, multicentre, multifaceted, social marketing hand-hygiene campaign. J hosp Infect, Vol. 74, pp. 225-231.

Fraise, A. (2011). Currently available sporicides for use in healthcare, and their limitations. J Hosp Infect, Vol. 77, pp. 210-212.

Garner, D., \& Machin, K. (2008). Investigation and management of an outbreak of mucromycosis in a paediatric oncology unit. J Hosp Infect, Vol. 70, No. 1, pp. 53-59.

Garner, J.S., \& Favero, M.S. (1986). CDC Guideline for handwashing and hospital environmental control, 1985. Infect Control, Vol. 7, pp. 231-243.

Garner, J.S., \& Favero, M.S. (1986). CDC guidelines for the prevention and control of nosocomial infections. Guideline for handwashing and hospital environmental control, 1985. Supersedes guideline for hospital environmental control published in 1981. Am J Infect Control, Vol. 14, pp.110-29.

Gill, A.W., Keil, A.D., Jones, C., Aydon, L., \& Biggs, S. (2011). Tracking neonatal nosocomial infection: the continuous quality improvement cycle. J Hosp Infect, Vol. 78, pp. 20-25.

Goroncy-Bermes, P., Koburger, T., \& Meyer, B. (2010). Impact of amount of hand rub applied in hygienic hand disinfection on the reduction of microbial counts on hands. J Hosp Infect, Vol. 74, pp. 212-218.

Gottrup, F. (2003). Prevention of surgical wound infections. N Eng J Med, Vol. 342, pp. 202-204.

Gould, D.J., Drey, N.S., \& Creedon, S. (2011). Routine hand hygiene by direct observation: has nemesis arrived. J Hosp Infect, Vol. 77, pp. 290-293.

Gudlaugsson, O., Gillispie, S., Lee, K., Vande Berg, J., Hu J., Messer, S., Herwaldt, L., Pfaller, M., \& Diekema, D. (2003). Attributable mortality of nosocomial candidemia, revisited. Clin Infect Dis, Vol. 37, pp. 1172-1177.

Halbawach, H. (1994). Solid waste disposal in District health facilities, Geneva. World Health Forum, Vol. 15, No. 4, pp. 363-367.

Hubner, N.O., Kellner, N.B., Partecke, L.I., Koburger, T., Heidecke, C.D., Kohlmann, T., \& Kramer, A. (2011). Determination of antiseptic efficacy of rubs on the forearm and consequences for surgical hand disinfection. J Hosp Infect, Vol. 78, pp. 11-15.

Hayette, M.P., Christiaens, G., Mutsers, J., Barbier, C., Huynen, P., Melin, P., \& de Mol, P. (2010). Filamentous fungi recovered from the water distribution system of a Belgian university hospital. Med Mycol, Vol. 48, No. 7, pp. 969-974.

Hugonnet, S., Harbarth, S., Sax, H., Duncan, R.A., \& Pittet, D. (2004). Nursing resources: a major determinant of nosocomial infection? Curr Opin Infect Dis, Vol. 17, No. 4, pp. 329-333.

Humphreys, P.N. (2011). Testing standards for sporicides. J Hosp Infect, Vol. 77, pp. 193-198. 
Ikram, A., Shah S.I.H., Naseem, S., Absar, S.F., Ullah, S., Ambreen, T., Sabeeh, S.M., \& Niazi, S.K. (2010). Status of hospital infection control measures at seven major tertiary care hospitals of northern Punjab. J Coll Physicians Surg Pak, Vol. 20, No. 4, pp. 266-70.

Institute for Healthcare Improvement. How-to guide: improving hand hygiene. A guide for improving practices among health care workers. Accessed 23 July 2011. Available from:

<http://www.ihi.org/knowledge/Pages/Tools/HowtoGuideImprovingHandHyg iene.aspx>

Jarvis, W.R. (2001). Infection control and changing health-care delivery systems. Emerg Infect Dis, Vol. 7, No. 2, pp. 170-173.

Jeans, A.R., Moore, J., Nicol, C., Bates, C., \& Read, R.C. (2010). Wristwatch use and hospitalacquired infection. J Hosp Control, Vol. 74, pp. 16-21.

Klevens., M.R., Edwards, J.R., Richards, J.C.L., Horan, T.C., Gaynes, R.P., Pollock D.A., \& Cardo D.M. (2007). Estimating health care-associated infections and deaths in U.S. hospitals, 2002. Public Health Rep, Vol. 122, pp. 160-166.

Kumar, S., Atray, D., Paiwal, D., Balasubramanyam, G., Duraiswamy, P., \& Kulkarni, S. (2011). Dental unit waterlines: source of contamination and cross-infection. J Hosp Infect, Vol. 74, pp. 99-111.

Landman, D., Chockalingam, M., \& Quale, J.M. (1999). Reduction in the incidence of methicillin-resistant Staphylococcus aureus and ceftazidime-resistant Klebsiella pneumoniae following changes in a hospital antibiotic formulary. Clin Infect Dis, Vol. 28, pp. 1062-1066.

Leung, M., \& Chan, A.H. (2006). Control and management of hospital indoor air quality. Med Sci Monit, Vol. 12, No. 3, pp. SR17-23. Epub 2006 Feb 23.

Loeb, M.B., Craven, S., McGeer, A.J., Simor, A.E., Bradley, S.F., Low, D.E., Armstrong-Evans, M., Moss, L.A., \& Walter, S.D. (2003). Risk factors for resistance to antimicrobial agents among nursing home residents. Am J Epidemiol, Vol. 157, pp. 40-47.

Lopman, B.A., Reacher, M.H., Vipond, I.B., Hill, D., Perry, C., Halladay, T., Brown, D.W., Edmunds, W.J., \& Sarangi, J. (2004). Epidemiology and cost of nosocomial gastroenteritis, Avon, England, 2002-2003. Emerg Infect Dis, Vol. 10, pp. 1827-1834.

Luby, S.P., Agboatwalla, M., Feikin, D.R., Painter, J., Billhimer, W., Altaf, A., \& Hoekstra, R.M. (2005). Effect of handwashing on child health: a randomised controlled trial. Lancet, Vol. 366, No. 9481, pp. 225-33.

Madani, T.A., Alsaedi, S., James, L., Eldeek, B.S., Jiman-Fatani, A.A., Alawi, M.M., Marwan, D., Cudal, M., Macapagal, M., Bahlas, R., \& Farouq, M. (2011). Serratia marcescenscontaminated baby shampoo causing an outbreak among newborns at King Abdulaziz University Hospital, Jeddah, Saudi Arabia. J Hosp Infect, Vol. 78, pp. 16-19.

Madeo, M. (2010). Efficacy of a novel antimicrobial solution (Prontoderm) in decolonizing MRSA nasal carriage. J Hosp Infect, Vol. 74, pp. 290-291.

Marchesi, I., Marchegiano, P., Bargellini, A., Cencetti, S., Frezza, G., Miselli, M., \& Borella, P. (2011). Effectiveness of different methods to control Legionella in the water supply: ten-year experience in an Italian university hospital. J Hosp Infect, Vol. 77, pp. 47-51. 
Marias, F., Mehtar, S., \& Chalkley, L. (2010). Antimicrobial efficacy of copper touch surfaces in reducing environmental bioburden in a South African healthcare facility. J Hosp Infect, Vol. 74, pp. 80-81.

Martinez-Capolino, C., Reyes, K., Johnson, L., Sullivan, J., Samuel, L., DiGiovine, B., Eichenhorn, M., Horst, H.M., Varelas, P., Mickey, M.A., Washburn R., \& Zervos, M. (2010). Impact of active surveillance on methicillin-resistant Staphylococcus aureus transmission and hospital resource utilization. J Hosp Infect, Vol. 74, pp. 232-237.

Mathai, E., Allegranzi, B., Kilpatrick, C., Nejad, S.B., Graafmans, W., \& Pittet, D. (2011). Promoting hand hygiene in healthcare through national/subnational campaigns. $J$ Hosp Infect, Vol. 77, pp. 294-298.

McNicholas, S., Andrews, C., Boland, K., Shields, M., Doherty, G.A., Murray, F.E., Smith, E.G., Humphreys, H., \& Fitzpatrick, F. (2011). Delayed acute hospital discharge and healthcare-associated infections: the forgotten risk factors. J Hosp Infect, Vol. 78, pp. 157-158.

McNulty, C., Logan, M., Donald, I.P., Ennis, D., Taylor, D., Baldwin, R.N., Bannerjee, M., \& Cartwright, K.A. (1997). Successful control of Clostridium difficile infection in an elderly care unit through use of a restrictive antibiotic policy. J Antimicrob Chemother, Vol. 40, pp. 707-711.

National Audit Office. (2000). The management and control of hospital acquired infections in acute NHS Trust in England. Report by the Comptroller and Auditor General, HC 230, Session 1999-00.

Pittet, D., \& Boyce, J.M. (2001). Hand hygiene and patient care: pursuing the Semmelweis legacy. Lancet Infect Dis, April, pp. 9-20.

Pittet, D., \& Donaldson, I. (2005). Clean Care is Safer Care: a worldwide priority. Lancet, Vol. 366, pp. 1246-1247.

Pittet, D., Panesar, S.S., Wilson, K., Longtin, Y., Morris, T., Allan, V., Storr, J., Cleary, K., \& Donaldson, L. (2011). Involving the patient to ask about hospital hand hygiene: a National Patient Safety Agency feasibility study. J Hosp Infect, Vol. 77, pp. 299-303.

Quale, J., Landman, D., Saurina, G., Atwood, E., DiTore, V., \& Patel, K. (1996). Manipulation of a hospital antimicrobial formulary to control an outbreak of vancomycinresistant enterococci. Clin Infect Dis, Vol. 23, pp. 1020-1025.

Rutala, W.A., \& Weber, D.J. Disinfection and sterilization in health care facilities: what clinicians need to know. Clin Infect Dis, Vol. 39, No. 5, pp. 702-709. Epub 2004 Aug 12.

Saurina, G., Quale, J.M., Manikal, V.M., Oydna, E., \& Landman, D. (2000). Antimicrobial resistance in Enterobacteriaceae in Brooklyn, NY: epidemiology and relation to antibiotic usage patterns. J Antimicrob Chemother, Vol. 45, pp. 895-898.

Scott, R.D. (2009). The direct medical cost of healthcare associated infections in U.S. hospitals and the benefits of prevention. Coordinating Center for Infectious Diseases, Centers for Disease Control and Prevention, March 2009. Accessed on 25 July 2011. Available from: <http://www.cdc.gov/ncidod/dhqp/pdf/scott_costpaper.pdf>

Shelton, C.L., Raistrick C., Warburton, K., \& Siddiqui, K.H. (2010). Can changes in clinical attire reduce likelihood of cross-infection without jeopardizing the doctor-patient relationship. J Hosp infect, Vol. 74, pp. 22-29. 
Siegel, J.D., Rhinehart, E., Jackson, M., \& Chiarello, L. (2007). Guideline for isolation precautions: preventing transmission of infectious agents in health care settings 2007. Am J Infect Control, Vol. 35, pp. S65-164.

Singh, I.B., \& Sharma, R.K. (1996). Hospital waste disposal system and technology. J Acad Hosp Adm, Vol. 8, No. 2, pp. 44-88.

Spaulding, E.H. (1968). Chemical disinfection of medical and surgical materials. In: Disinfection, sterilization, and preservation. Lawrence C., \& Block, S.S. pp. 517-531, Lea \& Febiger, Philadelphia.

Sroka, S., Gastmeier, P., \& Meyer, E. (2010). Impact of alcohol hand-rub on methicillinresistant Staphylococcus aureus: an analysis of the literature. J Hosp Infect, Vol. 74, pp. 201-211.

Stanton, M.W., \& Rutherford, M.K. (2004). Hospital nurse staffing and quality of care. Rockville, MD: Agency for Healthcare Research and Quality. Research in Action, Issue 14. AHRQ Pub. No. 04-0029.

Stone, P.W., Larson, E., \& Kawar, L.N. (2002). A systematic audit of economic evidence linking nosocomial infections and infection control interventions: 1990-2000. Am J Infect Control, Vol. 30, No. 3, pp. 145-152.

Tang, J.W., Noakes, C.J., Nielsen, P.V., Eames, I., Nicolle, A., Li, Y., \& Settles, G.S. (2011). Observing and quantifying airflows in the infection control of aerosol- and airborne-transmitted diseases: an overview of approaches. J Hosp Infect, Vol. 77, No. 3, pp. 213-222.

Trick, W.E., Weinstein, R.A., DeMarais, P.L., Kuehnert, M.J., Tomaska, W., Nathan, C., Rice, T.W., McAllister, S.K., Carson, L.A., \& Jarvis, W.R. (2001). Colonization of skilledcare facility residents with antimicrobial-resistant pathogens. J Am Geriatr Soc, Vol. 49, pp. 270-276.

Tsakris, A., Ikonomidis, A., Pournaras, S., Tzouvelekis, L.S., Sofianou, D., Legakis, N.J., \& Maniatis, A.N. (2006). VIM-1 metallo-beta-lactamase in Acinetobacter baumannii. Emerg Infect Dis, Vol. 12, pp. 981-983.

Uttley, A.H., \& Simpson, R.A. (1994). Audit of bronchoscope disinfection: a survey of procedures in England and Wales and incidents of mycobacterial contamination. J Hosp Infect, Vol. 26, pp. 301-308.

Wang, Y.L., Chen, W.C., Chen, C.C., Tseng S.H., Chien, L.J., Wu, H.S., \& Chiang, C.S. (2010). Bacterial contamination on surfaces of public areas in hospitals. J Hosp Infect, Vol. 74, pp. 195-196.

Weber, D.J., Rutala, W.A., \& DiMarino, A.J.Jr. (2002). The prevention of infection following gastrointestinal endoscopy: the importance of prophylaxis and reprocessing. In: Gastrointestinal diseases: an endoscopic approach. DiMarino, A.J.Jr, Benjamin, S.B., eds. pp. 87-106. Thorofare, Slack Inc., NJ.

White, H.A., \& Wiselka, M.J. (2011). Inpatient mortality and death reporting associated with Clostridium difficile infection in a large teaching hospital. J Hosp Infect, Vol. 77, pp. 369-370.

Widmer, A.F., Rotter, M., Voss, A., Nthumba, P., Allegranzi, B., Boyce, J., \& Pittet, D. (2010). Surgical hand preparation: state-of-the-art. J Hosp Infect, Vol. 74, pp. 112-122. 
World Health Organization. (2002). Prevention of hospital acquired infections - a practical guide. 2nd ed. Geneva: WHO, 2002. Document no. WHO/CDS/EPH/2002.12.

World Health Organization. (2009). WHO guidelines on hand hygiene in health care. Geneva: WHO, 2009.

World Health Organization. (2011). Report on the burden of endemic health care-associated infections worldwide. WHO Document Production Services, ISBN 9789241501507, Geneva.

Zing, W., Sandoz, L., Inan, C., Cartier, V., Clergue, F., Pittet, D., \& Walder, B. (2011). Hospital-wide survey of the use of central venous catheters. J Hosp Infect, Vol. 77, pp. 304-308. 


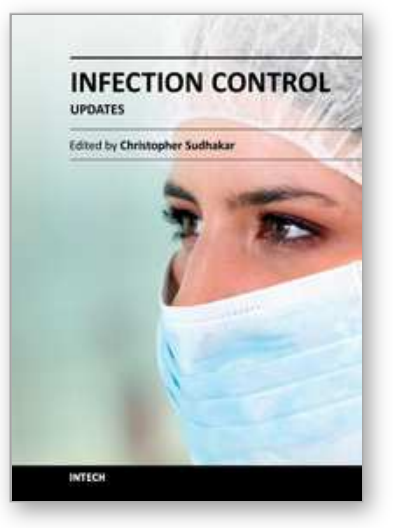

\author{
Infection Control - Updates \\ Edited by Dr. Christopher Sudhakar
}

ISBN 978-953-51-0055-3

Hard cover, 198 pages

Publisher InTech

Published online 22, February, 2012

Published in print edition February, 2012

Health care associated infection is coupled with significant morbidity and mortality. Prevention and control of infection is indispensable part of health care delivery system. Knowledge of Preventing HAI can help health care providers to make informed and therapeutic decisions thereby prevent or reduce these infections. Infection control is continuously evolving science that is constantly being updated and enhanced. The book will be very useful for all health care professionals to combat with health care associated infections.

\title{
How to reference
}

In order to correctly reference this scholarly work, feel free to copy and paste the following:

Aamer Ikram and Luqman Satti (2012). Healthcare Associated Infections: Nuisance in the Modern Medical Epoch, Infection Control - Updates, Dr. Christopher Sudhakar (Ed.), ISBN: 978-953-51-0055-3, InTech, Available from: http://www.intechopen.com/books/infection-control-updates/healthcare-associated-infections-anuisance-in-the-modern-medical-epoch

\section{INTECH}

open science | open minds

\author{
InTech Europe \\ University Campus STeP Ri \\ Slavka Krautzeka 83/A \\ 51000 Rijeka, Croatia \\ Phone: +385 (51) 770447 \\ Fax: +385 (51) 686166 \\ www.intechopen.com
}

\author{
InTech China \\ Unit 405, Office Block, Hotel Equatorial Shanghai \\ No.65, Yan An Road (West), Shanghai, 200040, China \\ 中国上海市延安西路65号上海国际贵都大饭店办公楼 405 单元 \\ Phone: +86-21-62489820 \\ Fax: $+86-21-62489821$
}


(C) 2012 The Author(s). Licensee IntechOpen. This is an open access article distributed under the terms of the Creative Commons Attribution 3.0 License, which permits unrestricted use, distribution, and reproduction in any medium, provided the original work is properly cited. 